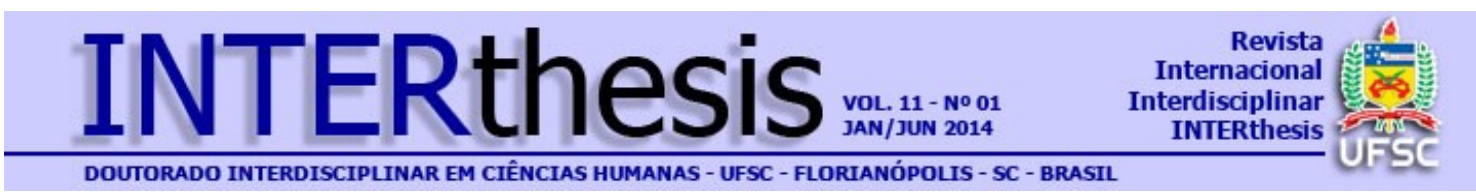

\title{
SOBRE A UNIVERSIDADE NO BRASIL NA ERA DO CHOQUE CULTURAL: A FORMAÇÃO PARA TECNOLOGIA ${ }^{1}$
}

Luiz Bevilacqua ${ }^{2}$

\begin{abstract}
Resumo
Vivemos numa era de mudanças que se caracteriza pela velocidade com que elas ocorrem. Essa é uma experiência única e sem qualquer padrão anterior que possa servir de orientação. A capacidade de observação e computação desenvolvida nesses últimos cem anos proporcionou a convergência de várias disciplinas. As barreiras departamentais se desmontaram dando origem a uma "nova ciência" caracteristicamente interdisciplinar. Se na pesquisa essa atitude está muito bem aceita, particularmente no que se refere a modelos, nos cursos de graduação é ignorada. É preciso encontrar novos eixos que atendam ao novo cenário científico e tecnológico. A oportunidade de criar novas Universidades no Brasil favorece a implantação de novos modelos cuja identidade seja mais adequada à formação dos jovens universitários. A maioria das nossas Universidades tradicionais está na rota de extinção. Urge ação imediata ousada e comprometida com o avanço do conhecimento. É preciso romper as amarras culturais de complexo de inferioridade e subserviência. Só assim poderemos de fato estar inseridos na comunidade internacional. Universidade centrada no aprendizado e não no ensino, pesquisa para avançar o conhecimento e não para engordar currículos, interdisciplinaridade como efeito e não como causa e recuperação da confiança mútua são itens indispensáveis para novas iniciativas. Os estudantes devem se preocupar com competência e não com diplomas, mais com independência intelectual do que com disciplinas. Sair da esteira e ir para a ponta no avanço do conhecimento. Menos protestos e mais propostas. E finalmente não se deixar bloquear por formalidades. A organização de cursos paralelos, modernos e informais, é uma ação lícita e necessária.
\end{abstract}

Palavras-chave: Choque Cultural. Interdisciplinaridade. Reorganização do Conhecimento. Fator Cultural. Nova Universidade.

\section{CONSIDERAÇÕES INICIAIS}

\footnotetext{
1 Este texto foi apresentado oralmente no Simpósio Internacional sobre Interdisciplinaridade no Ensino, na Pesquisa e na Extensão - Região Sul, em Outubro 2013, Florianópolis, SC, Brasil.

${ }^{2}$ Doutor em Mecânica Teórica e Aplicada pela Stanford University, EUA. Coordenador do Núcleo de Cognição e Sistemas da Fundação Universidade Federal do ABC. Professor Emérito da Coppe Instituto Alberto Luiz Coimbra de Pós-Graduação e Pesquisa de Engenharia e Pró-Reitor de Pesquisa e Pós-Graduação da Universidade Federal do Rio de Janeiro, Rio de Janeiro, RJ, Brasil. E-mail: bevilacqua@coc.ufri.br
}

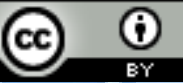


Uma época singular, nunca antes vivida e talvez nunca imaginada. A terra continua girando em torno do sol com a mesma regularidade milenar. Mas, as mudanças que se passam sobre esse minúsculo planeta sob a ação da parcela dos seus habitantes, que têm o singular predicado de se reconhecerem a si mesmos, evoluem com uma velocidade espantosa. A passagem de ano já não serve para plantar o marco que separa as mudanças impactantes das conquistas da nossa civilização. O nosso futuro passa agora a ser medido quase que literalmente pelo "amanhã". Dormimos dentro de um contexto e acordamos em outro. A figura retórica do "amanhã" perde o sentido elusivo para o seu significado restrito, o dia seguinte. Essa vertiginosa metamorfose não deixa tempo para fixar raízes o que significa correr o risco de eliminar a âncora da tradição particularmente para as novas gerações. ${ }^{3}$ Os mais conservadores projetam desastres mais ou menos catastróficos, que raramente se concretizam. Nós temos a extraordinária capacidade de resistir à extinção. Provavelmente, a própria reação às mudanças tem um papel importante no processo de evolução evitando rotas de extinção ou irrecuperáveis recuos civilizatórios. De alguma forma, todos nós vamos aceitando ou recusando as vertiginosas mudanças que nos invadem a vida. Seja individualmente, seja coletivamente, sem compromisso social ou institucionalmente, todos interagimos com a avalanche de acontecimentos que nos afetam a vida direta ou indiretamente. Há, no entanto, uma característica peculiar ao processo evolutivo que nos empurra para um novo mundo, é a aceleração com que isso acontece. Consequentemente, o abismo que separa gerações alarga-se rapidamente dificultando o diálogo entre gerações separadas por não mais do que uma dezena de anos. Ora uma das instituições mais importantes nesse processo é a Universidade, por ser o canal pelo qual uma fração considerável da população jovem passa enquanto as grandes mudanças estão em curso e cujas origens remetem à própria universidade. A formação dos estudantes passa a ser um processo dinâmico no qual convergem o

\footnotetext{
${ }^{3}$ Pode-se comparar esse fenômeno ao big-bang e ao universo inflacionário. Uma das hipóteses mais instigantes propõe que, após a explosão inicial, o universo evoluiu num primeiro estágio com mudanças relativamente pequenas. Após alguns instantes, inicia-se uma fase inflacionária em que o crescimento é exponencial. Se considerarmos o século XVIII como a época do big-bang científico, podemos dizer que a Era inflacionária começou em meados do século XX e está em plena evolução. Um acontecimento semelhante aconteceu há mais de 2000 anos. Nos anos 500 AC, os filósofos gregos deflagraram o big-bang do conhecimento ocidental cuja evolução deu origem a uma expansão inflacionária na Escola de Alexandria, tendo alcançado seu ápice nos anos 330 DC. Uma diferença essencial é que aparentemente a evolução atual está acontecendo na metade do tempo em que ocorreu a formação da cultura helênica.
}

R. Inter. Interdisc. INTERthesis, Florianópolis, v.11, n.1, p.43-65, Jan./Jun. 2014 
novo e o velho. Além disso, cabe à Universidade filtrar e anunciar à sociedade o que importa de mais relevante na avalanche de novidades que nos engolfam. É esta a mais importante atividade de extensão nos nossos dias. A Universidade tem, pois, um papel essencial, como sempre teve, na formação do arcabouço social, agora dentro de um novo contexto nunca antes experimentado; navegar num turbilhão de invenções, teorias, sucessos e fracassos que afetam diretamente a vida de todos nós.

Essa acelerada metamorfose é mais acentuada no que toca aos avanços tecnológicos e científicos. A era do conhecimento converteu-se na era do choque cultural. A metáfora da onda que observamos se elevar e logo desabar na areia é uma imagem muito adequada para representar o mundo em que estamos imersos. Não apenas pela inevitável violência do fenômeno, mas, também, porque os que ousam navegar nesse paredão de água necessitam de uma técnica totalmente diferente da que se usa em águas calmas. Nessas nadamos, na onda surfamos. Surfar não é um estilo de natação é uma ação totalmente diferente inclusive porque necessita de uma prancha. Do mesmo modo, para viver no tempo de choque cultural é necessário recorrer a outro tipo de atitude e ação. Não se trata de uma adaptação, uma maquiagem na estrutura vigente. Na realidade é necessária a reconstrução, a partir das fundações, do edifício da nossa cultura e da nossa atitude diante da vida. Essa atitude é um pressuposto para todos que se propõem a fazer da Universidade uma instituição capaz de responder aos desafios de nosso tempo. Despir-se não só dos preconceitos, mas dos próprios conceitos que sustentaram a estrutura universitária nos últimos cem anos.

A Universidade tem que estar profundamente comprometida com o novo contexto pela sua própria identidade que impõe a função de romper as fronteiras do conhecimento e simultaneamente ser a depositária do conhecimento universal. Essa dupla função aparentemente antagônicas a torna muito vulnerável a mudanças. A conhecida resistência da Universidade às mudanças, mesmo a pequenas mudanças, é um obstáculo para a abertura de novas janelas culturais, no sentido mais amplo. Ainda mais grave é a resistência a transformações profundas que abalam estruturas seculares, que se mostraram extremamente eficientes no passado. No entanto, a metamorfose em marcha exige a criação de uma "nova universidade", seja desconstruindo as estruturas arcaicas e reconstruindo novos modelos dentro das universidades tradicionais, seja como novas instituições livres

R. Inter. Interdisc. INTERthesis, Florianópolis, v.11, n.1, p.43-65, Jan./Jun. 2014
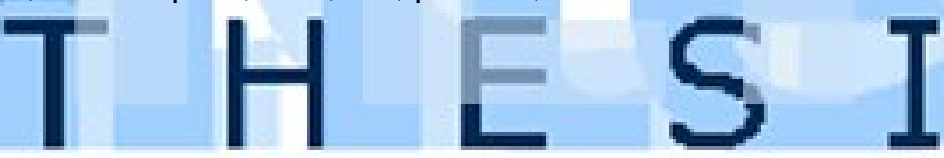
das amarras, que prevalecem hoje estabelecendo uma nova identidade capaz de responder aos desafios do nosso tempo. Existem muitas variantes que vem sendo adotadas em várias partes do mundo. Uma das mais comuns é a criação de institutos paralelos às universidades primariamente orientados à pesquisa, um ponto de encontro das várias especialidades temáticas tradicionalmente isoladas em departamentos na organização clássica. Essa solução tem sido comumente adotada em alguns países da Europa, nos EUA e Canadá. No Brasil, essa não deve ser a opção mais importante, pois nos faltam instituições de ensino superior. Melhor é construir as novas universidades em moldes adequados aos tempos modernos. Começar tendo em conta o turbilhão em que estamos metidos, além das enormes diferenças regionais que proporcionam nossa extensão territorial. O admirável nesse novo tempo é a liberdade de se propor novas estruturas acadêmicas. Não há modelo suficientemente testado que sirva de padrão para reproduzir novas iniciativas. É mais uma grande oportunidade que se tem no Brasil de abrir novos caminhos, livres, com independência intelectual, que frequentemente tanto nos falta. Reforma de estrutura acadêmica nas grandes e tradicionais universidades brasileiras é muito difícil, diria quase impossível. ${ }^{4}$ Isto é, sendo a estrutura universitária extremamente conservadora essa missão não pode ser realizada via os formalismos regimentais. Assim, a melhor opção, no caso das universidades clássicas, ${ }^{5}$ para levar à comunidade universitária, particularmente aos estudantes, a riqueza do mundo intelectual que se abre diante de nós nesse novo século é a via da informalidade. Essa alternativa, no entanto, se habilita os estudantes a se moverem com uma bagagem de conhecimento adequada ao mundo de hoje, não confere "diploma" que, infelizmente na nossa sociedade, é mais valorizado do que "competência". É uma opção que exige pouca aversão ao risco, muita criatividade, coragem, disposição, competência e espírito de aventura, características dos desbravadores.

\section{UMA PROPOSTA DE ESTRUTURA UNIVERSITÁRIA}

\footnotetext{
${ }^{4}$ Uma exceção digna de nota foi a reforma do projeto pedagógico da Universidade Federal da Bahia, promovida pelo então Reitor Prof. Naomar Almeida Filho, um Reitor como poucos com visão de futuro e, sobretudo coragem para enfrentar os reacionários de plantão.

${ }_{5}^{5}$ Refiro-me às Universidades Federais (UFRJ,UFMG,UFRGS, UFSC, UFPE,UFCE,UFPA, etc.) e às Estaduais (USP,UNICAMP,UNESP, UERJ, etc.) que já têm tradição e reconhecimento social.
}

R. Inter. Interdisc. INTERthesis, Florianópolis, v.11, n.1, p.43-65, Jan./Jun. 2014 
Antes de continuar devo me desculpar com os leitores por apresentar uma visão centrada nas áreas de ciências da natureza e tecnologia, é onde recolhi maior experiência. No entanto, as ideias fundamentais são universais. Vale considerar inicialmente a origem, ou melhor, as principais colunas que servem de base para os saltos científicos ocorridos nas últimas décadas. Creio que podemos selecionar três sem medo de errar:

1. Capacidade de observar o microcosmo. É fantástica a capacidade que desenvolvemos de perscrutar o íntimo da matéria. Nos últimos cem anos passamos da capacidade de observar micro-organismos ao atrevimento de manipular proteínas. Intervir nos processos vitais;

2. Capacidade de observar o macrocosmo. Aqui também em menos de cem anos a observação de telescópios instalados na terra evoluiu para telescópios instalados em satélites. Perscrutamos o universo profundo e colocamos sem cerimônia equipamentos em outros planetas para obter informações mais precisas; e

3. Capacidade de calcular. Mas se fomos capazes de progredir com extraordinária competência na arte de observar, nenhum avanço significativo teria sido possível sem a habilidade de calcular. Armazenar e manipular centenas de milhões de dados com altíssima velocidade foi essencial para o desenvolvimento científico e tecnológico. Foi o desenvolvimento de computadores com grande capacidade operacional que permitiu o surgimento de modelos matemáticos mais representativos dos fenômenos físico-químicos e sociais.

Esses três fatores combinados deram origem ao que podemos chamar uma "nova ciência", que é caracterizada pela convergência de disciplinas. De fato, nessa nova ciência, as barreiras interdisciplinares estão rompidas dando origem a temas que têm sido referidos como interdisciplinares. Pesquisas interdisciplinares, que em geral são classificadas como uma evolução da multidisciplinaridade a caminho da transdisciplinaridade, têm se firmado como a mais eficaz maneira de fazer avançar o conhecimento. A elaboração de modelos, incluindo um grande número de variáveis interagindo em gigantescos processos estocásticos que hoje são possíveis de ser tratados dado o desenvolvimento de computação alto desempenho, deu origem a uma nova abordagem de fenômenos físicos e sociais conhecida como teoria da complexidade. Com esse novo enfoque, procura-se descobrir como a natureza

R. Inter, Interdisc. INTERthesis, Florianópolis, v.11, n.1, p.43-65, Jan./Jun. 2014
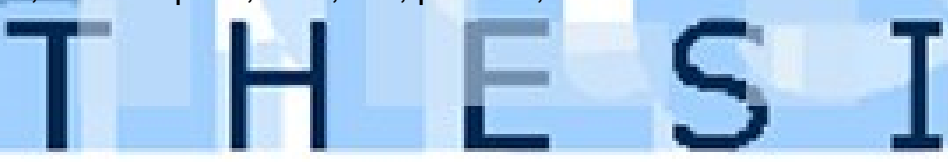
funciona na busca que nunca será abandonada pela teimosia humana: reduzir tudo a um conjunto de leis universais capazes de explicar todos os fenômenos físicos que ocorrem no universo. Inclusive com consequências sobre a própria evolução do gênero humano sugerindo, por exemplo, que somos necessários e não produto de um desdobramento puramente aleatório dada a um processo de auto-organização subjacente à trajetória de evolução. ${ }^{6}$

Então, o tripé, observação macro e micro conjugadas com computação, deflagrou um novo processo de organização do conhecimento. Os departamentos como organizados até hoje se tornaram supérfluos. A universidade como a concebemos até hoje está em fase de extinção. ${ }^{7}$ Mas, mesmo assim, aparentemente muitos preferem ficar alienados do que procurar novos caminhos, isto é, surfar. Para implantar uma nova universidade, cujo perfil como já dissemos não é único, devemos considerar que é preciso enfrentar alguns desafios. Como pré-condição:

- estar convencido de que a organização tradicional da universidade está esgotada;

- estar consciente de que não há muito tempo para pensar e decidir;

- será preciso assumir riscos;

- estar preparado para rápidas mudanças de rumo;

- será necessário questionar as velhas regras e lutar por novos estatutos mais flexíveis e adequados à dinâmica do nosso tempo;

- será necessário achar uma prancha adequada; e

- de qualquer forma estar preparado para cair e levantar.

A primeira tarefa consiste na definição do ethos, da identidade da universidade que se quer. É a fundação sobre a qual se constrói o projeto acadêmico. É fundamental que seja bem entendido pela comunidade universitária e que tenha a aderência da sua maioria. ${ }^{8}$ Agora peço licença para me referir à Universidade Federal do $\mathrm{ABC}$, por ser ela uma Universidade que foi instituída

\footnotetext{
${ }^{6}$ Ver por exemplo a sugestão proposta no livro de Stuart Kauffman, "At Home in the Universe", em que o autor sugere a possibilidade de que nós poderíamos ser considerados como um resultado esperado da evolução biológica.

${ }^{7}$ A propósito desse tema é interessante ler um artigo do Prof. Mark Taylor da Columbia University publicado em 27 de abril de 2009 no New York Times, sob o título: "End the University as we know it". 8 A universidade de Harvard declara: "A Harvard education is a liberal education-that is, an education conducted in a spirit of free inquiry undertaken without concern for topical relevance or vocational utility. This kind of learning is not only one of the enrichments of existence; it is one of the achievements of civilization."
}

R. Inter, Interdisc. INTERthesis, Florianópolis, v.11, n.1, p.43-65, Jan./Jun. 2014
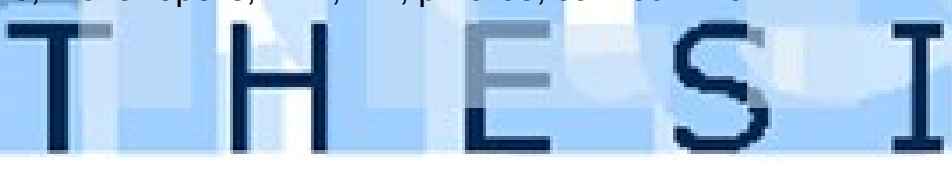
seguindo os padrões propostos nesse texto. Portanto, a nova proposta ganha concretude saído da esfera do possível para o terreno da existência. Os resultados estão sendo avaliados e embora não possa me referir a todos pelo menos alguns serão apresentados adiante. Se o modelo é sustentável ou não é um risco que precisamos correr. ${ }^{9}$ Feita essa observação, quero lembrar que o documento de fundação propõe o seguinte princípio orientador: "o principal compromisso da Universidade com a sociedade é a recuperação do gosto pelo conhecimento, mostrar as a beleza inerente aos mistérios da natureza ou escondida num conceito matemático" (UFABC, 2014, p. 1). ${ }^{10}$ Ela foi fundada com a perspectiva de que o conhecimento não é apenas um dos meios de resposta à demanda de mercado, mas, sobretudo, para o iluminamento do espírito humano (UFAB, 2014).

Essa é a identidade da UFABC que deve orientar todo o desenrolar do projeto acadêmico. Esse conceito primário, como se pode ver, propõe uma alteração na escala de valores vigente, o saber antecedendo o ter. É de fato o princípio mais fundamental que deve ser o guia dos desdobramentos práticos que passaremos a comentar.

Em primeiro lugar, o projeto pedagógico deve considerar a dinâmica do conhecimento que caracteriza a sociedade moderna. Uma das características que, aliás, não é recente na maioria das universidades espalhadas pelo hemisfério norte, mas desconsiderada em todas as universidades brasileiras, com raríssimas exceções, é dar aos estudantes a oportunidade da liberdade de escolha dos próprios caminhos. Os estudantes devem ser admitidos à Universidade e não a um curso específico. A opção da profissão, ou melhor, da formação que possa conduzir não necessariamente a uma profissão catalogada, deve ser uma escolha possível do estudante. A autoeducação deve ser uma prerrogativa do estudante nesse mundo moderno.

De fato, uma das características marcantes do nosso tempo é a mobilidade profissional. Mesmo dentro de uma mesma empresa, particularmente nas de grande porte, os profissionais são chamados a intervir em projetos que não se encaixam

\footnotetext{
${ }^{9}$ A pressa com que se quer mostrar resultados, muitas vezes induzida pelo próprio Poder Executivo, é uma decisão de alto risco. A UFABC deveria, desde o início, ter optado por um processo lento de crescimento para que professores, funcionários e estudantes pudessem apreciar melhor a totalidade da proposta. De qualquer modo as diretrizes gerais parecem que ainda seguem os padrões propostos pela comissão que desenhou o projeto acadêmico.

${ }^{10}$ Disponível em:

$<$ http://www.ufabc.edu.br/index.php?option=com content\&view=article\&id=17\&ltemid=71>. Acesso em: 03 fev. 2014.
}

R. Inter. Interdisc. INTERthesis, Florianópolis, v.11, n.1, p.43-65, Jan./Jun. 2014
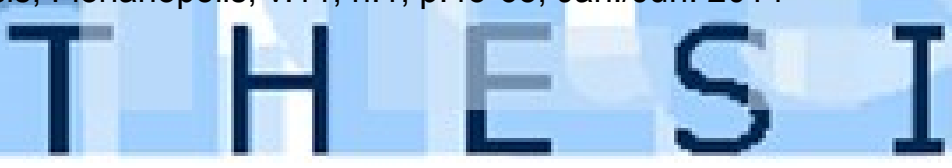
totalmente na sua formação universitária. Se a Universidade tiver estimulado a atitude de enfrentar desafios, buscar soluções, tomar iniciativas o jovem profissional terá como sair-se bem sucedido desse desafio. Por outro lado, dada essa característica de nosso tempo, a Universidade tem também que ampliar o alcance de sua atuação. Isso pode ser feito com a iniciativa de "portas abertas". Um bom estudante nunca é desligado da Universidade. A cerimônia de formatura não marca o encerramento da interação entre estudantes e Universidade, significa apenas uma passagem de um ciclo para outro. O bom estudante deve ser para sempre, nunca ser desligado e voltar sempre que for preciso.

A mobilidade tem ainda um aspecto mais universal. O jovem egresso da Universidade vê-se diante de várias opções de trabalho que não se conformam aos padrões tradicionais. Se a sua formação permitiu que fizesse escolhas, assumisse riscos e lutasse para vencer obstáculos, ele poderá aproveitar as oportunidades de trabalho sem se restringir a uma única alternativa muitas vezes sem oportunidade de emprego.

Outra característica importante é determinada pelas novas demandas da sociedade que não são atendidas pelas profissões não regulamentadas. Estão sendo criadas algumas novas profissões que não são regulamentadas nem se encaixam nas definições clássicas. Os jovens são muito perspicazes e capazes de detectar essas novas oportunidades. Se a Universidade facilitar uma formação adequada às novas demandas, combinada com o estímulo à inovação, os jovens egressos estarão muito mais aptos a enfrentar os novos desafios. A Universidade não deve se restringir à formar para o cenário profissional vigente, mas para o cenário profissional por vir.

Ainda é necessário considerar que a formação universitária não é exclusivamente para formar empregados, mas, também, para formar empregadores. É o que se tem chamado de empreendedorismo. A oportunidade de iniciar uma nova empresa deve estar dentro das opções dos estudantes. Em vários setores, tem ocorrido um estrangulamento na oferta de empregos, e a alternativa de se começar miniempresas ou consultorias individuais mais adequadas à situação atual se torna uma possibilidade importante e única em muitas situações. A formação universitária deve se preocupar com essa demanda que foge aos padrões clássicos determinados pelas confederações profissionais. Uma condição fundamental para atender a essas características profissionais é permitir a individualização, ainda que

R. Inter. Interdisc. INTERthesis, Florianópolis, v.11, n.1, p.43-65, Jan./Jun. 2014
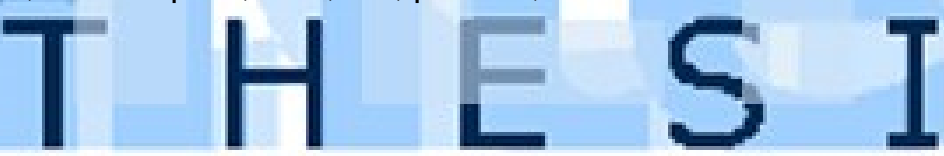
parcial, da grade curricular de modo que o estudante possa desenhar sua formação profissionalizante de acordo com sua vocação e suas aspirações.

De qualquer forma, para as carreiras tradicionais se deve estruturar o currículo profissional de modo a atender, tanto quanto possível, às demandas das tecnologias modernas e emergentes, e incorporar disciplinas que permitam uma inserção mais rápida dos formandos na sociedade moderna. É ainda importante considerar que não é mais possível formar um profissional pronto ou quase pronto para enfrentar os problemas práticos. As empresas são diversificadas, têm seus instrumentos próprios de trabalho. Inclusive, as denominadas universidades corporativas associadas a grandes empresas oferecem formação complementar focalizando as suas prioridades específicas. Essa tendência deve ser considerada na formação da grade curricular pelo menos em algumas Universidades. De fato, interessa aos empregadores, profissionais capazes de seguir sem grandes dificuldades, a formação complementar dentro da própria empresa. Isso significa que a organização curricular deve dar forte ênfase às ciências básicas. O conhecimento gerado a partir de pesquisas no campo das chamadas ciências básicas tem uma taxa de obsolescência muito mais reduzida do que as disciplinas profissionais. É ainda desejável ampliar o currículo básico em extensão e profundidade, no que diz respeito à Informática, Computação Científica, às Ciências Naturais, às Ciências da Engenharia e à Matemática.

No entanto, a formação com ênfase em ciências da natureza, matemática e tecnologia não é suficiente para a formação do cidadão educado. É indispensável que os egressos da Universidade conheçam o mundo em que vivem, nos seus diversos aspectos. Portanto, a grade curricular precisa incorporar disciplinas como, História das Civilizações, Motores do Desenvolvimento Humano, Geopolítica Contemporânea, Escolas Filosóficas, para dar alguns exemplos, com o intuito de desenvolver a capacidade crítica no exercício da atividade profissional e da cidadania.

Dentro desse novo arcabouço cultural, a definição e organização das disciplinas na nova Universidade é um tema muito importante. Deve ser capaz de responder aos novos desafios. Cada Universidade propõe a sua "marca", de acordo com a sua visão de mundo e o tipo de formação que considera mais adequado para os seus futuros egressos. Como estamos vivendo essa onda de choque cultural, as

R. Inter. Interdisc. INTERthesis, Florianópolis, v.11, n.1, p.43-65, Jan./Jun. 2014
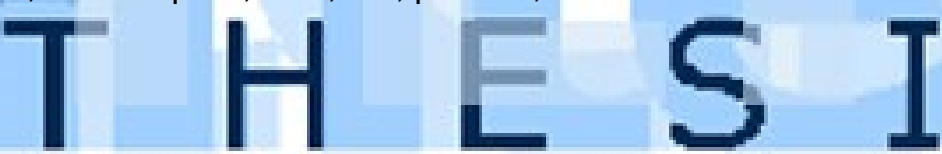
opções são extraordinariamente abertas. ${ }^{11}$ Os exemplos da Universidade de Harvard e da Universidade de Princeton são emblemáticos. Cada uma tem sua própria perspectiva de mundo e de formação a ser oferecida aos seus estudantes. No entanto, uma característica é comum: as barreiras disciplinares clássicas estão obsoletas. Estamos vivendo uma nova era e todo o currículo ou como é chamada, a meu ver com certa antipatia, a "grade curricular", parece uma prisão, deve ser totalmente reelaborado. Para isso, há uma condição indispensável começar tudo de novo. Adaptar as disciplinas em curso, fazer maquiagem é uma opção desastrosa. É preferível deixar como está.

Paralelamente à reforma curricular, que é um requisito universal, é preciso fazer florescer entre os estudantes nas nossas Universidades, e isso é um problema brasileiro, as habilidades de descobrir, inventar e sistematizar, características respectivamente das Ciências Naturais, das Engenharias e das Matemáticas para ficar limitado a alguns campos do saber. Dentre as várias ações para iniciar uma nova universidade gostaríamos de enfatizar:

- o estudante deve ingressar na Universidade e não em um curso;

- a estrutura das disciplinas que formam os fios condutores do conhecimento deve ser totalmente reelaborada, abandonando as diretrizes clássicas. Afinal são cem anos de construção do conhecimento. Impossível não haver impacto na formação universitária;

\footnotetext{
11 A Universidade de Harvard (2007) exige de todos os seus estudantes uma formação mais universal. Como requisito para graduação é necessário cursar "1. Aesthetic and Interpretive Understanding, 2. Culture and Belief, 3. Empirical Reasoning, 4. Ethical Reasoning, 5. Science of Living Systems, 6. Science of the Physical Universe, 7. Societies of the World, 8. The United States in the World", com as seguintes características: "We have therefore made an effort not to map these eight subject areas onto departments. We expect that some general education courses will involve collaborative teaching by faculty from different departments or even different divisions and Schools; other courses may be taught from a single disciplinary perspective" (HARVARD, 2007, p. 8). Princeton (2014) também tem suas orientações para os bacharelados em ciência e tecnologia: "Integrated Science is a revolutionary new introductory science curriculum developed at Princeton, intended for students considering a career in science. By breaking down traditional disciplinary barriers, a series of courses taken in the freshman and sophomore years provides students with first-rate preparation for a major in any of the core scientific disciplines, and in such a way that helps retain the connections to the other disciplines. The curriculum is founded on the expectation that much of the most important science of the future, though based on the classical disciplines, will lie in areas that span two or more of them. "Any budding researcher needs a foundation in several fields to be able to work on the most important problems confronting scientists today..." - David Botstein, director, Lewis-Sigler Institute for Integrative Genomics. The Integrated Science sequence is suitable for any undergrad. Considering concentrating in the sciences or engineering at Princeton. The core training is perfect preparation for a very broad range of careers, both within and outside science. The curriculum is especially valuable for students interested in bridging the traditional barriers between the biological and the physical sciences."
}

R. Inter. Interdisc. INTERthesis, Florianópolis, v.11, n.1, p.43-65, Jan./Jun. 2014

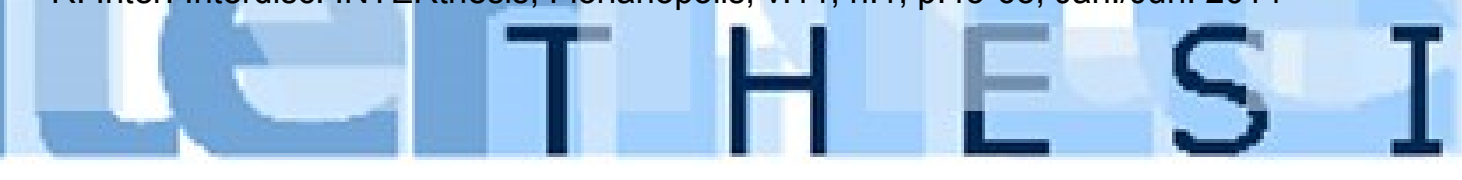


- ênfase na formação básica que é aquela que tem menor obsolescência;

- exceto por algumas disciplinas obrigatórias os estudantes devem ter liberdade na escolha de suas trajetórias curriculares. Além dos novos perfis profissionais que já estão vigorando é essencial que os estudantes tenham a coragem de assumir riscos;

- eliminar barreiras departamentais. O ideal é dissolver os departamentos. Estamos em plena era de interdisciplinaridade; e

- a formação universitária não pode ignorar que somos antes de tudo humanos e precisamos conhecer a nossa história e as relações políticas e sociais, que vão construindo (ou às vezes destruindo) a nossa civilização.

Gostaria de propor cinco princípios que considero muito importantes na estrutura universitária.

1. A universidade não é o lugar onde prioritariamente se ensina, mas, sobretudo, onde se aprende.

A tradição brasileira coloca no professor o foco do processo de ensinoaprendizado. Desde a escola primária até a universidade, embora nesta com menos gravidade, a ideia fundamental que perpassa a relação professor-aluno é que estes aprendem porque o professor ensina. Os estudantes são considerados recipientes de conhecimentos e rarissimamente geradores de conhecimento. Na realidade, os estudantes aprendem porque estudam e redescobrem o que thes é exposto. $\mathrm{O}$ professor ajuda, mas o maior responsável pelo aprender é o próprio estudante. E isso custa, dá trabalho. Uma prova cabal de que o conceito generalizado entre os professores é estudante recipiente, quase que inativo, é a quantidade absurda de disciplinas que se impõe nos currículos universitários. Não são necessárias 4000 horas de aulas, como exigido em algumas Universidades para se formar um engenheiro em 10 semestres. Representa em média 400 horas por período, 26 horas de exposição por semana, cerca de 78 horas de trabalho intelectual por semana ou mais de 10 horas por dia, 7 dias por semana. Com todos os argumentos de que muitas disciplinas não exijam muito tempo de reflexão, continua sendo absurdo. Mesmo reduzindo a 3000 horas ainda daria cerca de 10 horas, 6 dias por semana. O número exagerado de disciplinas serve mais para contratações de docentes do que para a boa formação dos estudantes. Professores devem ser contratados para áreas de conhecimento e não para ministrar disciplinas.

R. Inter. Interdisc. INTERthesis, Florianópolis, v.11, n.1, p.43-65, Jan./Jun. 2014
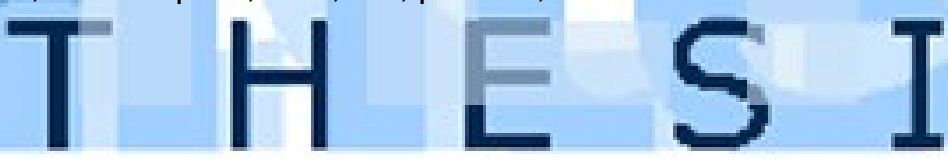
É necessária a redução drástica de horas de aula e de disciplinas para a formação dos jovens universitários. Urgente é oferecer espaço onde eles possam estudar na Universidade que deve ser sua casa de certa forma. A Universidade não é um colégio grande.

O mais importante é formar profissionais que sejam capazes de caminhar com suas próprias pernas e tomar decisões. Há que se formar a comunidade universitária com o foco no aprender, descobrir, inventar e criticar. Para isso é também necessário eliminar as separações rígidas entre graduação, pós-graduação, professores, pesquisadores e técnicos. Devemos viver uma comunidade universitária.

2. Não se deve colocar vinho novo em odres velhos.

Fala-se e pratica-se de fato a interdisciplinaridade nas investigações mais avançadas. Mas, os estudantes na sua primeira experiência universitária se deparam com eixos condutores do conhecimento iguais aos que prevaleciam na formação de seus avós.

A estrutura curricular hoje em vigor não serve mais. Não adiantam reformas curriculares com atualização de ementas. É necessário que os fios condutores da formação universitária sejam revistos. Não se trata de eliminar a boa ciência, a excelente base construída ao longo de séculos, mas de rearranjá-la em eixos integrados que traduzam os novos caminhos do progresso do conhecimento.

Aproveitando essa reorganização que não tem solução única, podia-se simultaneamente reduzir a carga horária e a quantidade de créditos para a formação acadêmica. Uma proposta que foi implantada na UFABC, pelo menos nominalmente, ${ }^{12}$ reorganiza os temas abordados nos eixos tradicionais: física, química, biologia, cálculo, em novos eixos:

- estrutura da material;

- energia;

${ }^{12}$ A redistribuição de conteúdos nesses novos eixos requer muito engenho e competência, principalmente porque os eixos, estruturas da matéria, energia e processos de transformação não podem ser elaborados independentemente, estão profundamente inter-relacionados. A elaboração de livros de textos segunda essas linhas é uma necessidade imperiosa como acentuou o prof. Alaor Chaves um dos gigantes no comitê que elaborou o projeto acadêmico da UFABC. A oportunidade de reestruturar um novo currículo acadêmico seguindo novas linhas mestras é uma oportunidade única para o Brasil, inclusive para não ficar totalmente dependente de diretrizes externas. Mas, não há muita gente capaz de ver essa vantagem. A nossa cultura está mais para a subserviência do que para a independência. Em lugar de antecipar iniciativas construtivas preferem-se os protestos a posteriori inúteis para reclamar dos fracassos.

R. Inter, Interdisc. INTERthesis, Florianópolis, v.11, n.1, p.43-65, Jan./Jun. 2014 
- informação e comunicação;

- processos de transformação; e

- modelagem, representação e simulação.

Os conteúdos desses eixos devem ser elaborados com o concurso de físicos, químicos biólogos, engenheiros e matemáticos. Não é fácil, mas é possível com uma boa dose de imaginação que às vezes falta a alguns docentes, mais por preguiça do que por desqualificação, e com certeza muita competência. Na realidade esses novos eixos estão muito mais adequados às prioridades atuais. $O$ leitor interessado pode consultar a organização temática das pesquisas no Helmholtz Institut ${ }^{13}$ que estão muito mais próximas dos eixos acima do que dos eixos tradicionais.

Outra inciativa muito importante para a formação dos estudantes, é oferecer disciplinas com conteúdos abertos, isto é, onde prevalece o desconhecido sobre conclusões bem fundamentadas, por exemplo: Floresta Amazônica; Surgimento e Evolução das Espécies; Formação do Universo; Conhecimento Racional e Transcendental; Deus, Crenças, Mitos e Religiões; Como Funciona o Cérebro. É importante imergir os estudantes em um ambiente de discussão onde a razão prevaleça sobre a emoção nos temas mais próximos da matemática, das ciências naturais e das ciências humanas e sociais. Por outro lado, não se deve bloquear a via da emoção que prevalece nas artes por exemplo, nem desvalorizar a intuição que é um processo de conhecer ainda por explorar com maior profundidade. Para completar o conjunto de requisitos, é necessário que os estudantes cursem disciplinas selecionadas nas áreas de ciências humanas e sociais.

\footnotetext{
${ }^{13} \mathrm{O}$ resumo dos focos de pesquisa obtido dos dados da Wikipedia está abaixo. O Helmholtz Institute é uma rede de Institutos de Pesquisa cujas siglas estão na descrição abaixo. "The works of the centres are categorised into programmes, which are divided into six research groups. The Helmholtz centres are grouped according to which research group they belong to: energy includes contributions from DLR, KIT, FZJ, GFZ, HZB, HZDR, IPP. Topics are Renewable energies, energy efficient conversion, nuclear fusion and nuclear safety; earth and environment is studied at AWI, DLR, FZJ, KIT, HZI, GFZ, HZG, HMGU, UFZ. Topics are the The changing earth, marine, coastal and polar systems, atmosphere and climate, biogeosystems and the topic terrestrial environment; health is studied the DKFZ, FZJ, KIT, HZI, DZNE HZG, HMGU, GSI, HZB, HZDR, MDC, and UFZ. This includes cancer research, cardio-vascular and metabolic disease research, (dys)function of the nervous system, infection and immunity, environmental health studies, comparative genomics for human health; key Technologies are studied at FZJ, KIT, HZG. In a single topic there is cooperations of the HZB; structure of Matter is studied at DESY, FZJ, KIT, HZG, GSI, HZB), HZDR. Topics are elementary and astroparticle physics, hadrons and nuclear physics, PNI-research (research with Photons, Neutrons andlons), aeronautics, space and transport research" (WIKIPEDIA, 2013).
}

R. Inter, Interdisc. INTERthesis, Florianópolis, v.11, n.1, p.43-65, Jan./Jun. 2014 
Finalmente, creio que é muito desejável que se estabeleça um núcleo orientado para o estudo das funções cerebrais, neurociência e cognição.

3. Primeiro descobrir e inventar, depois publicar.

A publicação serve prioritariamente para fazer avançar o conhecimento e não para avolumar o CV do autor. Recuperar o gosto pelo desafio de buscar novos caminhos abandonando a esteira do previsível. É importante que muitos em algum tempo se aventurem a percorrer novos caminhos sem compromissos com a ciência "bem estabelecida".

Falta-nos ousadia, e temas interdisciplinares são uma abertura para essa aventura. A ciência contabiliza muito mais fracassos do que sucessos. Mas, enquanto esses são contabilizados, aqueles são eliminados. Aprende-se muito com os fracassos, embora essas lições não sejam passíveis de publicação.

Uma das causas, talvez a principal, pela valorização da quantidade de publicações é o processo de avaliação dos cursos e progressão na carreira. Felizmente, algumas Agências de "Apoio" a Pesquisa, ${ }^{14}$ com certeza a FAPESP, abandonaram o critério quantitativo como prioritário, valorizando os trabalhos mais importantes produzidos pelo pesquisador.

Sem me alongar nesse ponto, embora reconhecendo a sua importância, convém comentar que os processos de avaliação de docentes estão equivocados.

4. Interdisciplinaridade não é causa é consequência.

Há um risco que ameaça inverter o processo de desenvolvimento natural da convergência disciplinar despertando montagens artificiais de grupos de investigação que colocam a interdisciplinaridade como motor primário e o avanço do conhecimento como consequência. Essa estratégia pode levar a superficialidades como tem sido observado por alguns críticos. A investigação interdisciplinar é uma exigência de muitas das novas áreas do conhecimento que se abriram recentemente. A modelagem de fenômenos naturais e sociais é uma das vertentes mais ricas e que abriu caminho para a chamada teoria da complexidade.

${ }^{14}$ É impressionante o nosso complexo de inferioridade que chega a batizar as agências de financiamento à pesquisa, particularmente as estaduais, de Fundação de Amparo em lugar de Apoio. É como se tudo estive caindo, desmontando. É contrário a uma atitude afirmativa de apoio.

R. Inter. Interdisc. INTERthesis, Florianópolis, v.11, n.1, p.43-65, Jan./Jun. 2014
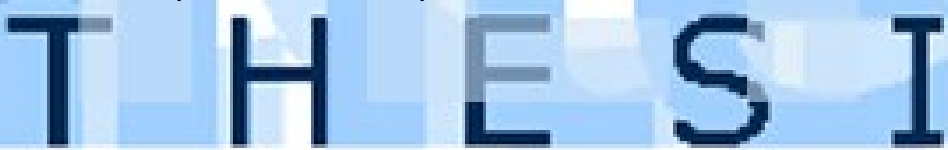
A aventura de pesquisa interdisciplinar é arriscada, e muitas vezes deixa os que optaram por essa via sujeito a fortes críticas da comunidade. ${ }^{15}$ É preciso arriscar o que é um invariante nas pesquisas verdadeiramente de ponta.

5. A Universidade é um todo monolítico e não uma colagem de partes.

Isto significa dizer que não se deve implantar uma Universidade "gradualmente". Primeiro graduação, depois, provavelmente cinco anos adiante, o mestrado, espera-se até "consolidar" e dai pode-se pensar em doutorado. Não há receita melhor para o fracasso. A Universidade é um conjunto inseparável de atividades que se não nascerem simultaneamente muito dificilmente se unirão mais tarde.

O cuidado que se deve ter é na velocidade de expansão tanto do corpo docente e técnico-administrativo como na admissão dos estudantes. Principalmente se o projeto de fato contempla uma nova cultura o crescimento deve ser gradual. Esse é um risco que correm as novas universidades que estão sendo criadas no Brasil. Muitas vezes as pressões políticas prejudicam sobremaneira a qualidade ensino, na ânsia de mostrar resultados rápidos, provoca-se o aborto. A Universidade Federal do $A B C$ foi criada de acordo com esses parâmetros. Até agora, os resultados são positivos no que se refere à contribuição ao avanço do conhecimento, ao desempenho dos estudantes e à internacionalização.

\footnotetext{
${ }^{15}$ O famoso físico Erwin Schrodinger (2012, p. 1) quando se aventurou a escrever sobre temas biológicos afirma no prefácio do seu livro "What is Life?" "[...] But the spread, both in width and depth, of the multifarious branches of knowledge during the last hundred odd years has confronted us with a queer dilemma. We feel clearly that we are only now beginning to acquire reliable material for welding together the sum-total of what is known into a whole; but, on the other hand, it has become next to impossible for a single mind fully to command more than a small specialized portion of it. I can see no other escape from this dilemma (lest our true aim be lost for ever) than that some of us should venture to embark on a synthesis of facts and theories, albeit with second-hand and incomplete knowledge of some of them, and at the risk of making fools of themselves. So much for my apologize".
}

R. Inter. Interdisc. INTERthesis, Florianópolis, v.11, n.1, p.43-65, Jan./Jun. 2014 


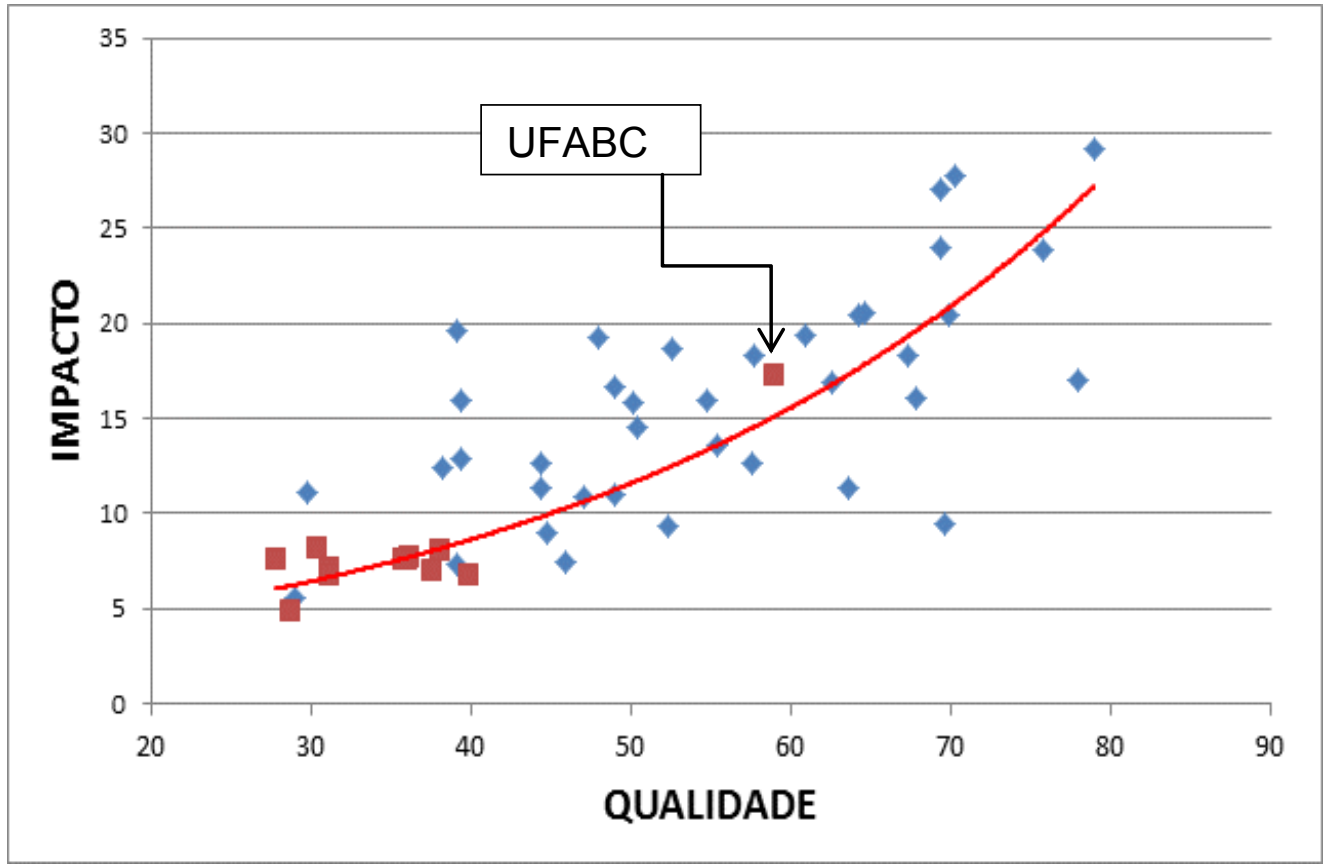

Fonte: Classificação SIR. Disponível em:

< http://www.scimagoir.com/pdf/SIR\%20Global\%202012\%200.pdf >.

No gráfico, qualidade significa a qualidade do meio de publicação e impacto o índice de citações, isto é, a importância da contribuição entre pares. Ele mostra a posição da UFABC num contexto internacional. A parte direita superior do gráfico é ocupada por Universidades de primeira linha, Harvard, Stanford, Cambridge, além de muitas outras. As Universidades brasileiras estão representadas por quadrados vermelhos. Claramente, a UFABC está numa posição muito boa, muito acima das outras Universidades brasileiras e mesmo acima da média mundial. Portanto, isso demonstra que nós podemos, o Brasil pode estar entre os melhores. Mas, como sempre acontece, aqui o desafio maior é manter essa posição. Quem viver verá. De qualquer forma, qualquer Governo minimamente competente deveria através das autoridades de educação superior acompanhar a evolução da UFABC e correlacionar o progresso ou retrocesso com os desvios do projeto inicial.

\section{O AMBIENTE CULTURAL BRASILEIRO}

Uma palavra final sobre o ambiente cultural em que estamos imersos. Qualquer que seja a atividade que façamos, ela está intrinsecamente ligada à nossa cultura. Sejam os pontos positivos, sejam os negativos, as nossas ações, decisões, projetos, intercâmbios sempre levarão a nossa marca. Infelizmente sofremos de um

R. Inter. Interdisc. INTERthesis, Florianópolis, v.11, n.1, p.43-65, Jan./Jun. 2014
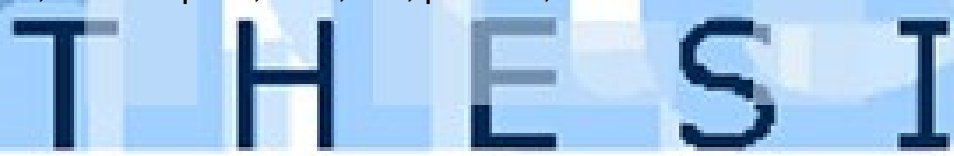
mal terrível que é o complexo de inferioridade, batizado pelo saudoso Nelson Rodrigues como "complexo de cachorro vira lata".

Esse caráter atávico é uma moeda e duas faces. Com relação ao mundo exterior, nos colocamos sempre em posição de inferioridade - antes mesmo de qualquer argumentação - e nas relações internas, fazemos uma discriminação extremamente rígida a partir de documentação formal. Assim, o diploma é superior à competência, implicando até na remuneração do trabalho. A erudição prevalece sobre o conhecimento específico. Os salários estão associados aos certificados, diplomas e papéis. Um excelente técnico numa Universidade, indispensável para a condução de pesquisa experimental, aulas de laboratório e manutenção de equipamentos sofisticados, nunca poderá ganhar como um professor 40 horas DE, mesmo que seu desempenho e contribuição à pesquisa sejam muito superiores aos do professor. Tremenda injustiça. Outra grave consequência, é a desvalorização do ensino técnico profissional. Um técnico não é inferior a um universitário, é simplesmente diferente. As principais características de independência intelectual, iniciativa, coragem para enfrentar novos desafios são igualmente acessíveis a ambos. $E$ é isso que vale, é isso que distingue a competência e confere valor profissional.

A escravidão à burocracia desumanizou os processos de avaliação de desempenho, conduzindo ao absurdo de tentar julgar tudo dentro dos estritos parâmetros objetivos. Impossível, só serve para criar desavenças e disputas legais que são totalmente estranhos ao espírito universitário. As planilhas de pontos para a promoção são absolutamente ridículas, parecem mais tabelas de pesos e medidas do que a avaliação do desempenho de um membro da comunidade universitária. As "métricas" de publicações, participação em bancas, e outros tipos de atividade são confrontados com os padrões que definem a "boa qualidade acadêmica" de cada nível preparada pelos "laboratórios de avaliação da produção acadêmica". O argumento de que as avaliações obedecem aos padrões atuais no intuito de serem objetivas é um engodo. Apenas um exemplo. Um trabalho publicado em qualquer revista, mesmo as de maior prestígio, depende essencialmente das avaliações subjetivas dos revisores. Portanto compra-se gato por lebre na antessala dos portais barrocos das avaliações acadêmicas em vigor nas nossas universidades.

Não sei por que não se enterra esse processo absurdo. Refletindo sobre as razões remotas da adoção desse processo, não é difícil de chegar à conclusão de

R. Inter, Interdisc. INTERthesis, Florianópolis, v.11, n.1, p.43-65, Jan./Jun. 2014
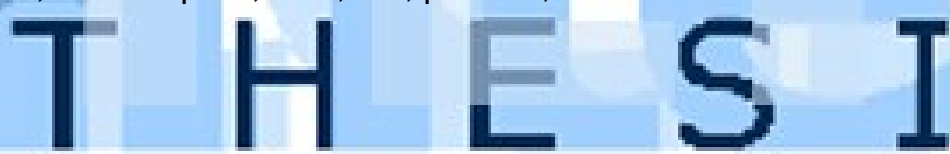
que a desconfiança generalizada está na raiz de tudo. A confiança mútua vem despencando nas últimas décadas. A hipótese fundamental que parece permear toda a sociedade, inclusive a academia, é que todos são hipócritas, falsos e interesseiros até que demonstrem o contrário. O progresso fica bloqueado, prisioneiro num emaranhado de regras, normas e leis que são continuamente contornadas o que gera uma nova onda de leis, regras e normas numa cadeia sem fim. Considerem a dificuldade de um estudante que se transfere de uma universidade à outra para reconhecer os créditos obtidos na universidade de origem. Um pequeno detalhe na ementa serve para não reconhecer a disciplina e obrigar o estudante a refazer a disciplina.

Voltando ao complexo de inferioridade, é importante lembrar que essa distorção de caráter é particularmente prejudicial ao progresso científico e ao processo de internacionalização. Na realidade, o processo de internacionalização é uma evolução natural. Basta criar o ambiente propício. Porém, muitas vezes caminhamos na direção oposta. Como participar de uma comunidade internacional, se desqualificamos uma das ferramentas mais importantes do mundo da ciência, ou seja, os veículos de comunicação, as revistas científicas. Nós mesmos através de instrumentos oficiais como o "Qualis" colocamos a maioria de nossos periódicos em situação inferior. Por que não encaminhamos alguns dos nossos melhores trabalhos para as nossas revistas? Como se pode ter a coragem de dizer que queremos estar inseridos na comunidade científica internacional se nos desqualificamos a nós mesmos. É semelhante a um anfitrião que convida seus amigos mais nobres para um jantar, mas pede que eles tragam a sua própria comida pois a que será servida é muito ruim. Será essa casa colocada no rol das que valem a pena ser visitadas? Por outro lado somos mestres em supervalorizar tudo o que vem de fora. É comum se ver nos congressos nacionais, praticamente em todos os setores, a lista de conferencias especiais preenchida só por cientistas estrangeiros, nenhum brasileiro. Eu me pergunto, se não temos nada a dizer, ou estamos engatinhando e, portanto, não há que se falar em internacionalização no sentido que se tem proposto, ou o complexo de inferioridade está abaixo de zero. Enquanto não levantarmos a cabeça, jamais poderemos fazer parte da comunidade internacional.

Mas, ainda há esperança. Talvez um fio de esperança mas ainda viva. Devemos construir em lugar de nos entrincheirarmos. A juventude clama nas passeatas "em defesa de" quando devia gritar "em favor de". Mas, para estar "em

R. Inter, Interdisc. INTERthesis, Florianópolis, v.11, n.1, p.43-65, Jan./Jun. 2014
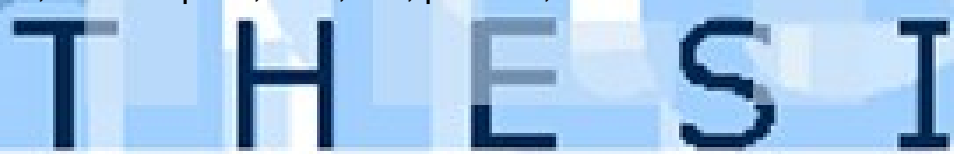
favor de" é preciso ter propostas, é preciso pensar construtivamente. A nossa juventude não está sendo formada para resolver, mas para reclamar. É preciso aprender a ter coragem e determinação para enfrentar situações inexploradas, sem referências. Sair da esteira do conhecimento e ir para a fronteira. Ousar!

Como foi dito no início, estamos numa época de grandes avanços científicos e tecnológicos, os instrumentos de troca de conhecimento são múltiplos e cada vez mais eficientes. É preciso fazer a imaginação funcionar. A TI (Tecnologia de Informação) é uma das nossas pranchas para surfar na onda de choque cultural. Ampliar a colaboração interna entre as nossas Universidades em vez de estimular processos de competição destrutiva até a difamação em alguns casos.

Coragem para atender ao clamor do novo mundo e da nova ciência. Não há soluções únicas, é preciso aproveitar essa oportunidade impar para deixar o ensino superior com a liberdade de que precisa para progredir com vários modelos.

Estamos de fato no limite da instabilidade no sistema educacional brasileiro, agitado com greves, violências, oposições sem posições. Se um país estrangeiro quisesse interferir na nossa educação para prejudicá-la, não precisaria fazer nada, é só deixar andar como está. Mas, não podemos ficar paralisados, pelo menos os que na comunidade acadêmica se importam em preservar e levar adiante os valores acadêmicos universais cujas raízes têm origens na cultura helênica (Alexandria séculos 330 AC a $300 \mathrm{DC})$. Ficam duas sugestões:

1. os que têm a oportunidade de começar uma nova Universidade que o façam com liberdade de explorar novos caminhos que respondam melhor aos desafios do século XX. Estar comprometido profundamente com o conhecimento científico, estimular o aprendizado e a capacidade de independência intelectual dos estudantes, menor preocupação com os conselhos profissionais, maior inserção na comunidade internacional como pares e não como subordinados. Sobretudo valorização mérito acadêmico; e

2. os que estão em universidades tradicionais não vejo outra alternativa, exceto em casos muito excepcionais, senão iniciar atividades paralelas, informais mas regulares, sem necessidade de aprovação em Conselhos que permitam os estudantes a ter acesso a um conhecimento organizado sem barreiras departamentais. Dá muito trabalho, não pode ser realizado sem a participação dos estudantes mais dedicados ao progresso do saber.

R. Inter. Interdisc. INTERthesis, Florianópolis, v.11, n.1, p.43-65, Jan./Jun. 2014
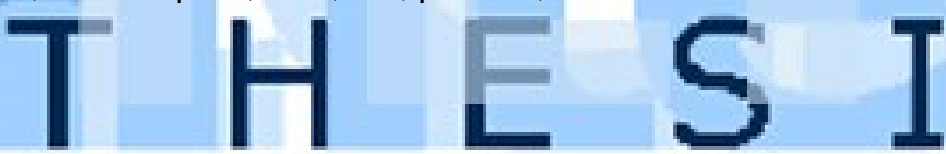
É a semente de uma nova Universidade que possivelmente virá superar a antiga já em fase de extinção funcional.

Devo pedir desculpas pelo excesso de indignação que às vezes me assalta e não posso evitar traduzir em palavras. Assim, finalizo essa reflexão com a esperança de poder ver ainda nos meus dias uma verdadeira revolução na educação brasileira. Uma revolução a favor de uma universidade que tenha sua identidade inspirada nos tempos de Alexandria.

R. Inter. Interdisc. INTERthesis, Florianópolis, v.11, n.1, p.43-65, Jan./Jun. 2014
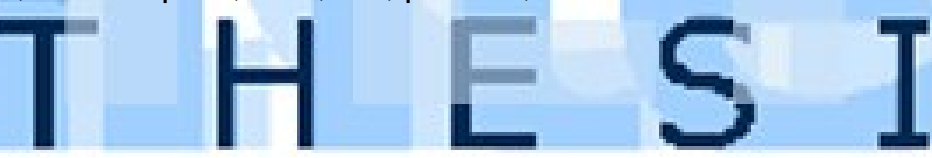


\title{
ABOUT THE UNIVERSITY IN BRAZIL IN THE ERA OF THE CULTURAL SHOCK. EDUCATION FOR TECHNOLOGY
}

\begin{abstract}
We live in an era of change which is characterized by the speed with which it occurs. This is a once-in-a-lifetime experience and without any previous standard which can serve as guidance. The ability of observation and computing developed in the last hundred years has given the convergence of various disciplines. Departmental barriers have disassembled giving rise to a "new science" characteristically interdisciplinary. If in research that attitude is very well accepted, particularly as regards the models, in the undergraduate courses, it is ignored. We must find new axes that meet the new scientific and technological scenario. The opportunity to create new universities in Brazil favors the deployment of new models whose identity is more suitable for the education of young university students. Most of our traditional universities are on route to extinction. It urges immediate action - bold and committed to the advancement of knowledge. We must break the cultural chains of the inferiority complex and subservience. Only in this way can we actually be inserted into the international community. Universities focusing on learning and not on teaching, research to expand the knowledge and not to fatten resumes, interdisciplinarity as an effect and not as a cause, as well as the recovery of mutual trust are essential items for new initiatives. Students must worry about competence and not about diplomas, worry more about intellectual independence than about disciplines; get off the treadmill and go to the top advancements of knowledge; protest less and make more proposals; and finally, not let themselves be blocked by formalities. The organization of parallel courses, informal and modern, is a lawful and necessary action.

Keywords: Cultural shock. Interdisciplinarity. Reorganization of knowledge. Cultural Factors. New University.
\end{abstract}

\section{SOBRE LA UNIVERSIDAD EN BRASIL EN LA ERA DEL CHOQUE CULTURAL: LA FORMACIÓN PARA LA TECNOLOGÍA}

\section{Resumen}

Vivimos en una era de cambios que se caracteriza por la velocidad con que ocurren. Esta es una experiencia única para la cual no hay antecedentes que puedan servir de orientación. La capacidad de observación y computación desarrollada en los últimos cien años proporcionó la convergencia de varias disciplinas. Las barreras departamentales se desmontaron dando origen a una "nueva ciencia" característicamente interdisciplinar. Si en la investigación esa actitud es aceptada en buenos términos, particularmente en lo que se refiere a los modelos, en los cursos de graduación es ignorada. Es preciso encontrar nuevos ejes a la altura del nuevo escenario científico y tecnológico. La oportunidad de crear nuevas Universidades en Brasil favorece la implantación de nuevos modelos cuya identidad sea más adecuada a la formación de los jóvenes universitarios. La mayoría de nuestras Universidades tradicionales está a camino de la extinción. Urge acción inmediata osada y comprometida con el avance del conocimiento. Es preciso romper las amarras culturales de complejo de inferioridad y servidumbre. Sólo así podremos de hecho estar inseridos en la comunidad internacional. Universidad centrada en el aprendizaje y no en la enseñanza, investigación para avanzar el conocimiento y no para engordar currículos, interdisciplinariedad como efecto y no como causa y

R. Inter, Interdisc. INTERthesis, Florianópolis, v.11, n.1, p.43-65, Jan./Jun. 2014

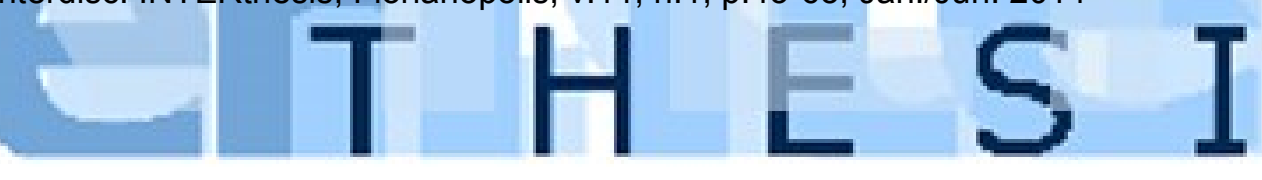


recuperación de la confianza mutua son ítems indispensables para las nuevas iniciativas. Los estudiantes deben preocuparse con su competencia y no con diplomas, más con independencia intelectual de que con disciplinas. Salir de la retaguardia e ir para los primeros lugares en el avance del conocimiento. Menos protestas y más propuestas. Y finalmente no dejar bloquearse por formalidades. La organización de cursos paralelos, modernos e informales, es una acción lícita y necesaria.

Palabras-clave: Choque Cultural. Interdisciplinariedad. Reorganización del Conocimiento. Factor Cultural. Nueva Universidad.

R. Inter, Interdisc. INTERthesis, Florianópolis, v.11, n.1, p.43-65, Jan./Jun. 2014
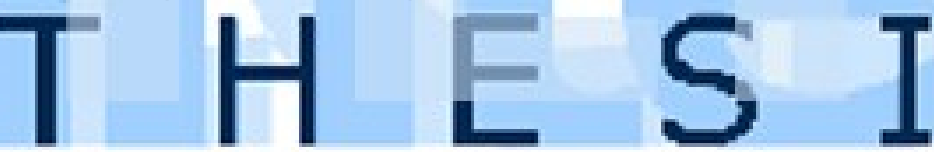


\section{REFERÊNCIAS}

HARVARD UNIVERSITY. Report of the Task Force on General Education. 2007. Disponível em: $<$ http://

http://www.sp07.umd.edu/HarvardGeneralEducationReport.pdf>. Acesso em: 03 fev. 2014.

PRINCETON UNIVERSITY. What is integrated Science? 2014. Disponível em: <http://http://www.princeton.edu/integratedscience/>. Acesso em: 03 fev. 2014.

SCHRODINGER, E. What is life? Nova lorque: Cambridge University Press, 2012.

UFABC. Criação. 2014. Disponível em:

$<$ http://www.ufabc.edu.br/index.php?option=com content\&view=article\&id=17\&ltemid =71>. Acesso em: 03 fev. 2014.

WIKIPEDIA. Helmholtz Association of German Research Centres. 2013. Disponível em: <http://

http://en.wikipedia.org/wiki/Helmholtz Association of German Research Centres>. Acesso em: 03 fev. 2014. 